\title{
Catheter entrapment due to severe radial artery spasm during transradial approach
}

\author{
Ertuğrul Zencirci ${ }^{1}$, Aleks Değirmencioğlu ${ }^{2}$ \\ ${ }^{1}$ Department of Cardiology, Acibadem Maslak Hospital, Istanbul, Turkey \\ ${ }^{2}$ Department of Cardiology, Acibadem Universtiy School of Medicine, Istanbul, Turkey
}

\begin{abstract}
Background: Catheter entrapment due to severe radial artery spasm (RAS) during transradial coronary catheterization has been rarely reported and its management is not precisely defined. The aim of this study was to determine the incidence, predictors and management of catheter entrapment due to severe RAS.

Methods: A total of 723 patients undergoing transradial coronary catheterization at a single center were retrospectively enrolled in the present study. Patients were divided into two groups: those with catheter entrapment due to severe RAS and those without.

Results: The incidence of catheter entrapment was 0.8\%. Height (161.2 $\pm 9.1 \mathrm{~cm}$ vs. $169.6 \pm$ $\pm 10 \mathrm{~cm}, p=0.047)$ and body surface area $(1.86 \pm 0.04$ vs. $1.95 \pm 0.18, p=0.002)$ were found to be lower, and total procedure time $33.2 \pm 13.4 \mathrm{~min} v \mathrm{~s} .15 .2 \pm 12.3 \mathrm{~min}, p<0.001$ ) was longer in the entrapment group. Multivariate logistic regression analysis demonstrated that total procedure time independently predicted catheter entrapment (odds ratio: 1.057, 95\% confidence interval [CI] 1.004-1.114, $p=0.035)$. Receiver-operating characteristic curve demonstrated good diagnostic accuracy for prolonged total procedure time in predicting catheter entrapment (area under curve $=0.8,95 \%$ CI 0.63-0.97, $p=0.01$ ). Patients were effectively treated with stepwise administration of systemic vasodilators, forearm heating, sedation and as a last resort general anesthesia with no significant complication.

Conclusions: Catheter entrapment due to severe RAS during transradial approach was rare and prolonged total procedure time is an independent predictor of catheter entrapment. Treatment with stepwise administration of different treatment modalities is possible with no significant complication. (Cardiol J 2016; 23, 3: 324-332)
\end{abstract}

Key words: catheter entrapment, radial artery spasm, transradial approach

\section{Introduction}

In the preceding two decades, the transradial approach for coronary interventions has proven to be safe and feasible in different clinical situations with a markedly decreased incidence of major access-site complications and early patient ambulation compared to transfemoral approach [1-4].

Although radial artery has become more popular vascular access route for coronary interventions across the world, one of the major and well-defined disadvantages of the transradial approach is radial

Address for correspondence: Ertuğrul Zencirci, MD, Department of Cardiology, Acıbadem Maslak Hospital, Buyukdere C. No: 40, 34457, Maslak/Sarıyer, İstanbul, Turkey, tel: +90 5323746446, fax: +90 2122859314, e-mail: ertuzencirci@gmail.com

Received: 01.02.2016 Accepted: 07.05.2016 
artery spasm (RAS) which causes severe discomfort and switch to transfemoral approach [5-8]. Previous studies have reported the incidence, risk factors and management of RAS during transradial approach [7-10]. Severe RAS can cause the vessel to clamp down on the catheter, resulting in catheter entrapment which causes severe pain while attempting to manipulate catheter. Catheter entrapment limits the successful completion of transradial catheterization and its management constitutes a major challenge. However, studies focusing on catheter entrapment due to severe RAS are lacking.

In this study, the authors' aim was to investigate the incidence, predictors and management of catheter entrapment due to severe RAS during transradial coronary interventions.

\section{Methods}

\section{Patients}

A total of 723 patients undergoing transradial coronary catheterization at the institution of Acrbadem Maslak Hospital, between October 2013 and December 2014, were retrospectively enrolled into the present study. Eligible were all patients aged $\geq 18$ years with clinical indication for diagnostic coronary angiography or percutaneous coronary intervention (PCI), in whom the right or left radial artery could be successfully cannulated. Approval of local Ethics Committee was obtained before starting the study, which was performed in accordance with the ethical standards specified in the Declaration of Helsinki.

\section{Procedure}

All procedures were performed by 3 interventional cardiologists experienced in radial interventions at a single center that performs transradial approach as default strategy in the cardiac catheterization laboratory. Our clinic is a secondary center where an average of 750 coronary interventions are performed annually and the percentage of transradial approach is about $80 \%$ of all coronary interventions. The right radial approach was the default approach for vascular access. Left radial artery was the preferred site in patients with previous coronary artery bypass grafting using a left internal mammary artery or in patients in whom right radial artery was occluded. Barbeau test was performed at baseline to confirm the presence of dual circulation and patency of the palmar arch [11]. Absence of return of the ulnar artery signal within
2 min after cessation of compression was defined as an abnormal Barbeau test.

Routinely, a 6 Fr short $(7 \mathrm{~cm})$ hydrophilic sheath (Radiofocus Introducer II, Terumo, Tokyo, Japan) was introduced. To prevent RAS, depending on operator's preference, $100-200 \mu \mathrm{g}$ nitroglycerin and/or $2 \mathrm{mg}$ verapamil were injected through the side port of the sheath. To prevent thrombosis, $70 \mathrm{IU} / \mathrm{kg}$ unfractionated heparin was also injected through the side port of the sheath. Selective angiography of radial, brachial, or subclavian artery was only performed if difficulty was encountered during guidewire or catheter advancement. The underlying cause (spasm or anatomical variation) was determined and at operator's discretion, continued with either extra intra-arterial administration of nitroglycerin and/or verapamil or with primary access site conversion. Verapamil was not administrated in patients with hypotension, bradycardia, high-grade atrioventricular block, myocardial infarction complicated with cardiogenic shock, moderate to severe left ventricular systolic dysfunction, or significant aortic stenosis. Nitroglycerin was also not administrated in patients with significant aortic stenosis, hypotension, or myocardial infarction complicated with cardiogenic shock. Sedative agents are not routinely used for coronary angiography, and this usually depends on operator's preference.

For diagnostic procedures, a single diagnostic universal 5 Fr Tiger catheter (Terumo, Leuven, Belgium) was used. Judkins, Amplatz, multipurpose and pigtail 5 Fr or 6 Fr catheters were also used when needed. For coronary interventions, 6 Fr Judkins, EBU, and Amplatz guiding catheters (Medtronic, USA) were used.

In case of planned or ad-hoc PCI, an additional bolus of $30 \mathrm{IU} / \mathrm{kg}$ unfractionated heparin was administrated. Platelet glycoprotein IIb/IIIa inhibitors were administered as clinically indicated during the procedure. The radial sheath was immediately removed at the end of the procedure and a radial compression device (TR Band, Terumo, Tokyo, Japan) was applied at the access site.

\section{Data collection}

The clinical and angiographic data of all patients were reviewed retrospectively. Demographics of the patients and angiographic data such as radial artery site, total procedural time, the number of catheters used, administration of nitroglycerin and verapamil, and catheter entrapment were all recorded. Total procedure time was defined as the time interval between the initiation of the puncture 
to the radial artery to the completion of the last coronary angiographic view.

\section{Clinical definition of radial artery} spasm and catheter entrapment

Operator-assessed RAS was determined based on a questionnaire addressing 5 signs:

- persistent forearm pain;

- pain response to catheter manipulation;

- pain response to sheath withdrawal;

- difficult catheter manipulation after being trapped by radial artery;

- considerable resistance on withdrawal of the sheath.

Patients presenting with at least 2 of these 5 signs were diagnosed as having clinical RAS [12]. Catheter entrapment was defined as severe local pain associated with catheter trapping which restricts manipulation of catheter due to severe RAS [13].

\section{Exclusion criteria}

Exclusion criteria included: 1) Failure of sheath and/or catheters insertion into the radial artery due to RAS and/or severe tortuosity which results in transfemoral switch $(\mathrm{n}=2) ; 2)$ Inadequte data collection $(n=14)$.

\section{Statistical analysis}

Quantitative variables were expressed as mean \pm standard deviation, and qualitative variables were expressed as percentage (\%). Data were tested for normal distribution using the Kolmogorov-Smirnov test. A comparison of parametric values between the two groups was made using a 2-tailed Student's t-test, and for nonparametric values Mann-Whitney U test was used. Categorical variables were compared using the $\chi^{2}$ test or Fisher's test. Binary logistic regression analysis was used to evaluate independent association between catheter entrapment and clinical parameters. The relationship between total procedure time and catheter entrapment was analyzed using the area under the receiver operator characteristic curve (AUC). A p value of $<0.05$ was considered statistically significant. All statistical analyses were carried out using SPSS version 18.0 (SPSS, Chicago, IL, USA).

\section{Results}

The study population consisted of 723 patients (mean age $63 \pm 10$ years, range $27-90,239$ women) undergoing transradial coronary catheterization.
Patients were divided into two groups; those with catheter entrapment $(+), \mathrm{n}=6(0.8 \%)$ and those without catheter entrapment $(-), \mathrm{n}=716(99.2 \%)$. The baseline clinical characteristics of patients included in the study are presented in Table 1 .

Height $(161.2 \pm 9.1 \mathrm{~cm}$ vs. $169.6 \pm 10 \mathrm{~cm}, \mathrm{p}=$ $=0.047)$ and body surface area $(1.86 \pm 0.04$ vs. $1.95 \pm 0.18, \mathrm{p}=0.002$ ) were found to be significantly lower in the entrapment group. Other baseline clinical characteristics were not different between the two groups ( $p>0.05$ ).

Ninety-nine percent of the study patients had transradial coronary catheterization via a right radial access. Thirty-two point six percent of the study patients had acute coronary syndrome, $21.5 \%$ underwent $\mathrm{PCI}$, and $8.6 \%$ had primary $\mathrm{PCI}$. A redo transradial approach was performed in 3.9\% of all patients. Combination of nitroglycerin and verapamil was administrated in $42 \%$ of the study patients. Diagnostic coronary angiography was performed using $5 \mathrm{Fr}$ diagnostic catheters in the large majority of the patients (73.9\%). Six Fr guiding catheters were used in all of the patients requiring coronary interventions. Procedural characteristics were similar in both groups except for total procedure time $(33.2 \pm 13.4$ min vs. $15.2 \pm$ \pm 12.3 min, $\mathrm{p}<0.001$ ) (Table 2).

The incidence of RAS was $14.1 \%(n=102)$ and the incidence of catheter entrapment due to severe RAS was very low with an incidence of $0.8 \%$ $(\mathrm{n}=6)$. Catheter entrapment was encountered in $4(0.7 \%)$ diagnostic procedures, and in $2(1.3 \%)$ therapeutic procedures $(\mathrm{p}=0.61)$. Table 3 shows the baseline and procedural characteristics of patients with catheter entrapment.

The effects of different variables on catheter entrapment were calculated in univariate analysis for each. The variables for which the unadjusted $\mathrm{p}$ value was $\leq 0.10$ in logistic regression analysis were identified as potential risk markers and included in the full model. Female sex, height, and total procedure time were analyzed with multivariate logistic regression model. Multivariate logistic regression analysis demonstrated that total procedure time independently predicted catheter entrapment (odds ratio: $1.057,95 \%$ confidence interval [CI]: 1.004-1.114, $\mathrm{p}=0.035$ ) (Table 4). Prolonged total procedure time was defined by total procedure time higher than $20.5 \mathrm{~min}$, which was derived from receiver-operating characteristic (ROC) curve analysis. In the analysis of ROC curve, prolonged total procedure time demonstrated good diagnostic accuracy in predicting catheter entrapment $(\mathrm{AUC}=0.8,95 \%$ CI: 0.63-0.97, $\mathrm{p}=0.01)$ (Fig. 1). 
Table 1. Clinical characteristics of the study group.

\begin{tabular}{|c|c|c|c|}
\hline & $\begin{array}{c}\text { Entrapment }(+) \\
\text { group }(n=6)\end{array}$ & $\begin{array}{l}\text { Entrapment }(-) \\
\text { group }(n=717)\end{array}$ & $\mathbf{P}$ \\
\hline Age [years] & $56 \pm 17.7$ & $60.2 \pm 10.8$ & 0.81 \\
\hline Women & $4(66.7 \%)$ & $235(32.8 \%)$ & 0.08 \\
\hline Height $[\mathrm{cm}]$ & $161.2 \pm 9.1$ & $169.6 \pm 10$ & 0.047 \\
\hline Weight $[\mathrm{kg}]$ & $82.2 \pm 7.2$ & $83.4 \pm 12.6$ & 0.81 \\
\hline Body surface area & $1.86 \pm 0.04$ & $1.95 \pm 0.18$ & 0.002 \\
\hline Diabetes mellitus & $2(33.3 \%)$ & $225(31.4 \%)$ & 0.99 \\
\hline Hypertension & $3(50 \%)$ & $378(52.7 \%)$ & 0.89 \\
\hline Coronary artery disease & $2(33.3 \%)$ & $190(26.5 \%)$ & 0.66 \\
\hline Smoking & $1(16.7 \%)$ & $197(27.5 \%)$ & 0.99 \\
\hline Systolic BP [mm Hg] & $117.8 \pm 18.9$ & $128.2 \pm 20.6$ & 0.22 \\
\hline Diastolic BP [mm Hg] & $71.7 \pm 11.6$ & $75.2 \pm 10.9$ & 0.43 \\
\hline Heart rate $[\mathrm{bpm}]$ & $79.8 \pm 11.1$ & $76.5 \pm 14.7$ & 0.62 \\
\hline Fasting glucose [mg/dL] & $118.2 \pm 24.9$ & $121.4 \pm 41.8$ & 0.87 \\
\hline Total cholesterol [mg/dL] & $214.8 \pm 50.9$ & $203.7 \pm 47.7$ & 0.64 \\
\hline LDL cholesterol [mg/dL] & $155 \pm 42.9$ & $132.9 \pm 40.3$ & 0.28 \\
\hline HDL cholesterol [mg/dL] & $41.3 \pm 4.2$ & $42.8 \pm 13.4$ & 0.82 \\
\hline \multicolumn{4}{|l|}{ Clinical presentation: } \\
\hline Stable angina pectoris & $2(33.3 \%)$ & $376(52.4 \%)$ & \multirow{3}{*}{0.42} \\
\hline Acute coronary syndromes & $2(33.3 \%)$ & $234(32.6 \%)$ & \\
\hline Other conditions & $2(33.3 \%)$ & $107(14.9 \%)$ & \\
\hline \multicolumn{4}{|l|}{ Medications: } \\
\hline ACE-I & $4(66.7 \%)$ & $321(44.8 \%)$ & 0.28 \\
\hline Beta-blocker & $1(16.7 \%)$ & $303(42.3 \%)$ & 0.21 \\
\hline Calcium-channel blocker & $2(33.3 \%)$ & $123(17.2 \%)$ & 0.28 \\
\hline Nitrate & $0(0 \%)$ & $47(6.60 \%)$ & 0.99 \\
\hline
\end{tabular}

ACE-I — angiotensin converting enzyme inhibitor; BP — blood pressure; HDL — high density lipoprotein; LDL — low density lipoprotein

Patients were treated with stepwise administration of systemic vasodilators, forearm heating, sedation, and, as the last resort, general anesthesia. As a first step treatment, systemic vasodilators; intravenous $2.5-5 \mathrm{mg}$ verapamil, $200-400 \mu \mathrm{g}$ nitroglycerin or sublingual $0.4-0.8 \mathrm{mg}$ glyceryl trinitrate were administrated to all patients with entrapment. However, none of the patients responded to systemic vasodilators. As a second step treatment, forearm heating was effectively applied with a convective air patient warming system (Warm Touch, model WT-5300 A, Covidien, Mansfield, USA) up to $15 \mathrm{~min}$ at $43^{\circ} \mathrm{C}$ in 2 patients (Fig. 2). As a third step treatment, sedation with intravenous midazolam 1-2 mg was effective in 3 of the patients with persistent entrapment. Finally, general anesthesia was needed in a patient who was still unresponsive to all previous treatments.
Only 1 patient with entrapment suffered from radial artery occlusion without hand ischemia.

\section{Discussion}

In the present study, it was shown that catheter entrapment due to severe RAS during transradial approach is rare and prolonged total procedure time is an independent predictor of catheter entrapment. Effective stepwise treatment with systemic vasodilators, forearm heating, sedation, and general anesthesia is possible with no significant complication.

Radial artery spasm is one of the major challenges of transradial coronary interventions. Radial artery is particularly prone to vasospasm due to its muscular nature and $\alpha$-adrenoceptor-predominance [14]. Both circulating catecholamines through activation of $\alpha_{1}$-adrenoreceptor and mechanical stimuli 
Table 2. Procedural characteristics of study group.

\begin{tabular}{|c|c|c|c|}
\hline & $\begin{array}{c}\text { Entrapment }(+) \\
\text { group }(n=6)\end{array}$ & $\begin{array}{l}\text { Entrapment (-) } \\
\text { group }(\mathrm{n}=717)\end{array}$ & $\mathbf{P}$ \\
\hline Previous transradial intervention & $0(0 \%)$ & $12(1.7 \%)$ & 0.99 \\
\hline Radial artery site right/left & $6 / 0(100 \% / 0 \%)$ & $710 / 7(99 \% / 1 \%)$ & 0.99 \\
\hline Nitroglycerine + verapamil & $1(16.7 \%)$ & $303(42.3 \%)$ & 0.21 \\
\hline Catheter: & & & 0.7 \\
\hline 5 Fr diagnostic & $4(66.7 \%)$ & $530(73.9 \%)$ & \\
\hline 6 Fr diagnostic & $0(0 \%)$ & $34(4.7 \%)$ & \\
\hline 6 Fr guiding & $2(33.3 \%)$ & $153(21.3 \%)$ & \\
\hline Number of catheters used & $1.3 \pm 0.5$ & $1.5 \pm 0.7$ & 0.47 \\
\hline Total number of catheters & & & 0.96 \\
\hline 1 & $4(66.7 \%)$ & $394(55 \%)$ & \\
\hline 2 & $2(33.3 \%)$ & $275(38.4 \%)$ & \\
\hline 3 & $0(0 \%)$ & $42(5.9 \%)$ & \\
\hline 4 & $0(0 \%)$ & $2(0.3 \%)$ & \\
\hline 5 & $0(0 \%)$ & $4(0.6 \%)$ & \\
\hline Primary $\mathrm{PCl}$ rate & $1(16.7 \%)$ & $61(8.5 \%)$ & 0.42 \\
\hline Total $\mathrm{PCl}$ rate & $2(33.3 \%)$ & $154(21.5 \%)$ & 0.62 \\
\hline Total procedure time [min] & $33.2 \pm 13.4$ & $15.2 \pm 12.3$ & $<0.001$ \\
\hline Following ipsilateral transradial intervention & $0(0 \%)$ & $28(3.9 \%)$ & 0.99 \\
\hline Operators: & & & 0.49 \\
\hline Operator 1 & 211 & 3 & \\
\hline Operator 2 & 259 & 2 & \\
\hline Operator 3 & 247 & 1 & \\
\hline
\end{tabular}

$\mathrm{PCl}$ - percutaneous coronary intervention

(sheath introduction, guidewire and catheter manipulation) cause smooth muscle cell contraction which results in RAS [14, 15].

Many preventive measures have been suggested to prevent spasm of radial artery, such as sedation, adequate analgesia, hydrophilic coated sheaths, and intra-arterial vasodilators $[7,8,16]$. Various drugs have been extensively evaluated to prevent spasm of radial artery but there is currently no agreement on the optimal agents. Majority of previous reports advocated the use of intra-arterial vasodilators, most frequently verapamil and/or nitrogylcerin $[7,8,16,17]$. In a head to head comparison study between nitroglycerin and verapamil, there was no statistically significant difference in the incidence of RAS [18]. Although data from the SPASM trial [16] show that intra-arterial application of vasodilators is safe, recent data from the active-controlled SPasmolytic Agents to avoid SpasM during transradial percutaneous coronary interventions (SPASM3) trial [19] suggest that the administration of any of the tested vasodilators may be accompanied by adverse events. Verapamil is contraindicated in patients with hypotension, bradycardia, high-grade atrioventricular block, myocardial infarction complicated with cardiogenic shock, moderate to severe left ventricular systolic dysfunction, or significant aortic stenosis. Nitroglycerin is also contraindicated in patients with significant aortic stenosis, hypotension, and cardiogenic shock. Furthermore, a recent study indicated that beyond the learning curve preventive administration of intra-arterial verapamil offers no advantage over ad hoc application in terms of access site conversion rates [20]. In our center, in appropriate cases, a bolus of intra-arterial nitroglycerin and/or intra-arterial verapamil is given prophylactically.

According to previous studies, the incidence of RAS has varied considerably between $2 \%$ and $34 \%$ due to the inconsistency in prophylactic therapy and criteria for diagnosis [7-10]. However, severe RAS is less frequent and the incidence of severe limiting spasm resulting in femoral crossover is 


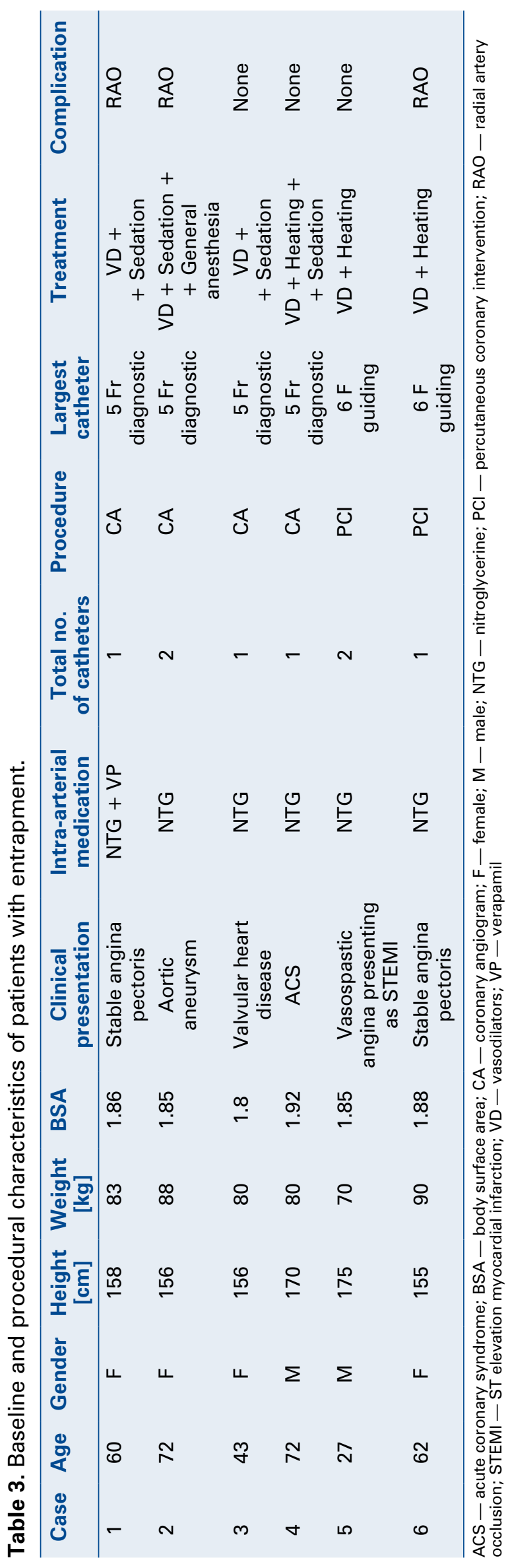

Table 4. Effects of variables on catheter entrapment in univariate and multivariate logistic regression analyses.

\begin{tabular}{lcc}
\hline & $\begin{array}{c}\text { Odds ratio } \\
(95 \% \mathrm{Cl})\end{array}$ & $\mathbf{P}$ \\
\hline Univariate predictors & & \\
Female sex & $4.102(0.746-22.557)$ & 0.1 \\
Height & $0.918(0.836-1.009)$ & 0.075 \\
$\begin{array}{l}\text { Total procedure } \\
\text { time [min] }\end{array}$ & $1.063(1.023-1.105)$ & $\mathbf{0 . 0 0 2}$ \\
$\begin{array}{l}\text { Multivariate predictors } \\
\text { Total procedure }\end{array}$ & \\
time [min] & & \\
\hline
\end{tabular}

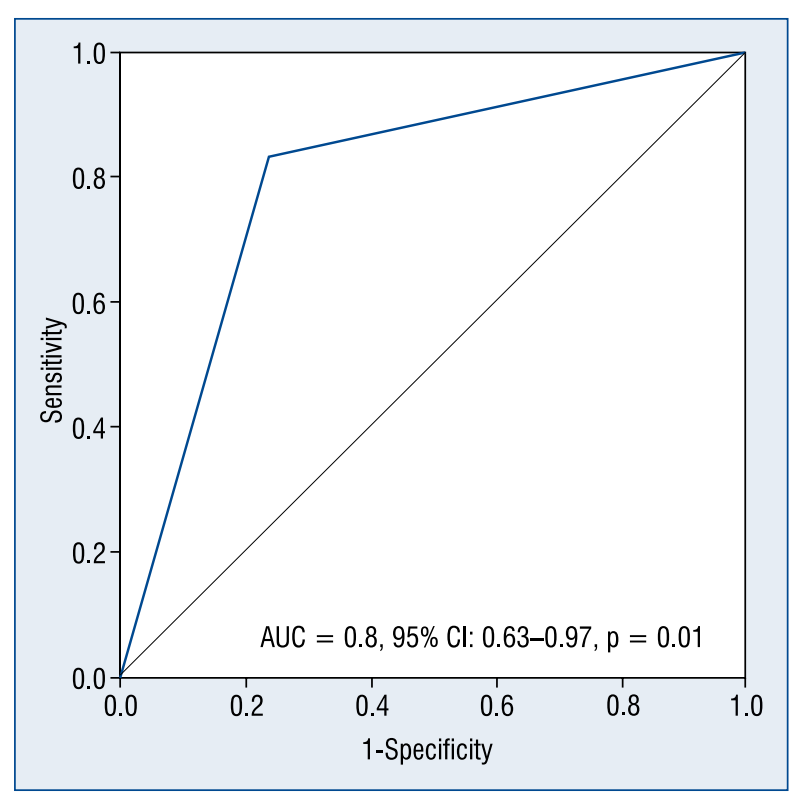

Figure 1. Receiver operating characteristic curve analysis for prolonged total procedure time in predicting catheter entrapment; AUC - area under curve; $\mathrm{Cl}$ - confidence interval.

$0.7 \%[13,19]$. In the present study, the incidence of RAS and severe RAS was found to be correlated with these previous findings and to the best of our knowledge, this is the first report that reveals the incidence of catheter entrapment due to severe RAS. Catheter entrapment can also be due to catheter kinking which is rare in experienced hands [21]. This can be prevented with avoiding over manipulation of catheter. However, in the present study, catheter entrapment due to catheter kinking was not encountered.

Several RAS-associated factors have been identified, including patient-related factors (female 


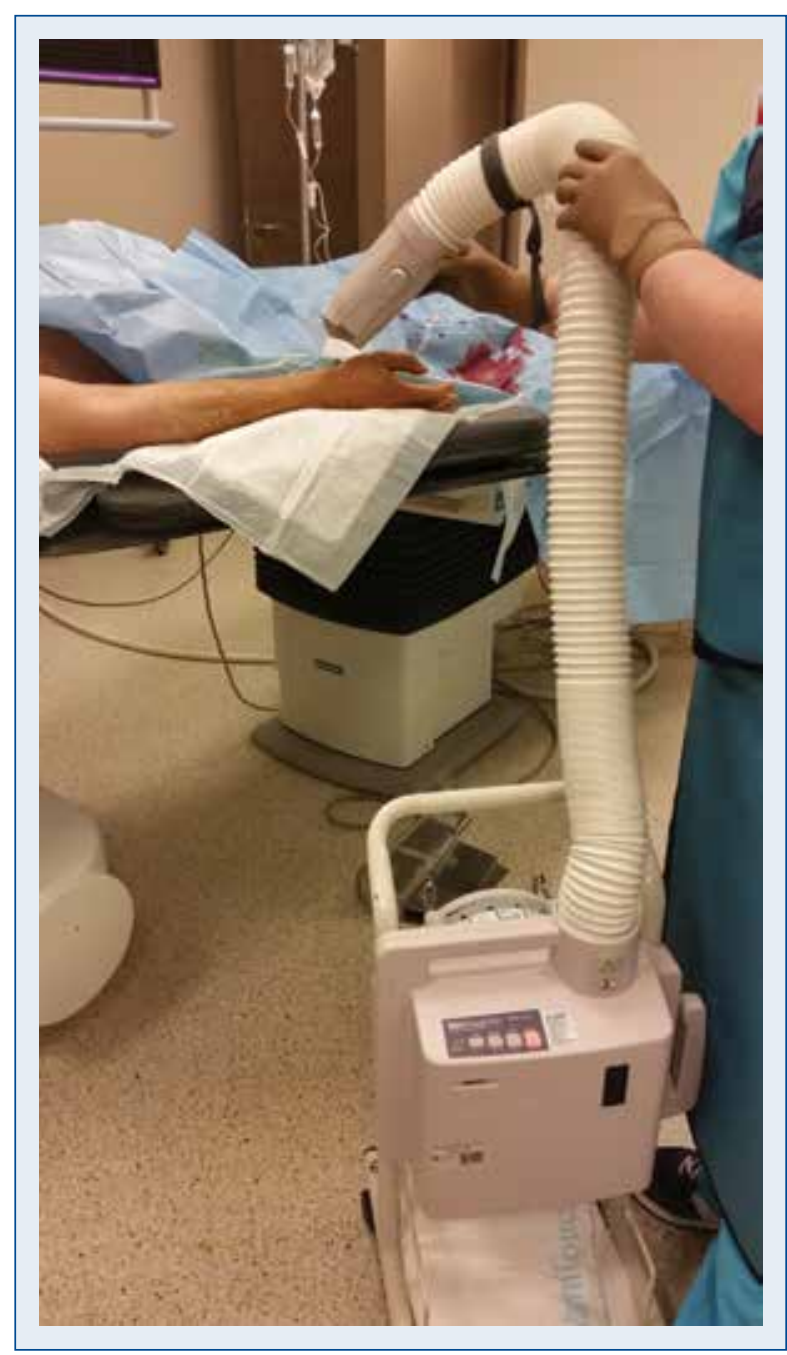

Figure 2. Forearm heating with a convective air patient warming system (Warm Touch, model WT-5300 A, Covidien, Mansfield, USA) in a patient with catheter entrapment.

gender, young age, low body mass index, short stature, small radial artery diameter, diabetes mellitus, dyslipidemia, anxiety, anomalous radial artery), and technical factors (low radial artery to sheath ratio, non-hydrophilic coated sheaths, unsuccessful access at first attempt, prolonged cannulation, multiple catheter exchanges, excessive catheter manipulations, limited operator experience) $[8,13$, $15-17,22-24]$. In the present study, it was demonstrated that the catheter entrapment-associated factors were similar to these previously defined factors.

Several pharmacological agents have been proposed in the management of RAS. In case of severe RAS causing catheter entrapment, the use of intra-arterial nitroglycerin, verapamil, sublingual nitroglycerin, and even the use of intra-arterial papaverine with lidocaine have been proposed $[8,25]$. In the present study, as a first step treatment, systemic vasodilators, verapamil and/or nitrates were administrated to all patients with entrapment.

Management of pharmacoresistant RAS causing catheter entrapment has not been precisely defined. Heating has been shown to be a stimulus evoking conduit artery dilatation. It was previously demonstrated that heating induces radial artery vasodilation through flow-mediated dilatation [26]. Increased local temperature has been documented to modulate $\alpha_{1}$-adrenergic receptor-mediated vasoconstriction by augmenting the release of endothelial cell-derived vasodilators [27]. Nitric oxide and endothelium-derived hyperpolarizing factor are involved in flow-mediated dilatation. The present study demonstrated that forearm heating, as a second step treatment, might be successful in the management of catheter entrapment.

Sedation with anxiolytics has been suggested as a means to reduce the incidence of spasm as vasospasm can be triggered by procedure-related anxiety and pain [8]. Recently, low doses of an opioid/benzodiazepine (fentanyl/midazolam) combination has been reported to be associated with a substantial reduction in the rate of RAS [28]. Besides the sedative and analgesic action, benzodiazepines also have direct vasoactive effects. Midazolam was shown to induce vasodilation and attenuate the vasoconstrictive response to adrenergic stimuli [29]. Thereby midazolam might have a role in the prevention and reversal of vasospasm in the setting of adrenergic overactivation situations, such as cardiac catheterization-related stress. In the present study, sedation with intravenous midazolam as a third step treatment was effective in patients with catheter entrapment. Thus, sedation with intravenous midazolam in conjunction with other treatments can be effective in case of catheter entrapment.

In case of persistent catheter entrapment due to resistant severe RAS despite all the treatments, general anesthesia can be an effective last resort strategy as in the case of the present study $[8,30]$. General anesthesia attenuates neurogenic influences contributing to RAS.

The present study suggested a management strategy of catheter entrapment with stepwise administration of different treatment modalities. The algorithm is outlined in Figure 3.

\section{Limitations of the study}

The most important limitations of the present study were that it was retrospective and conducted 


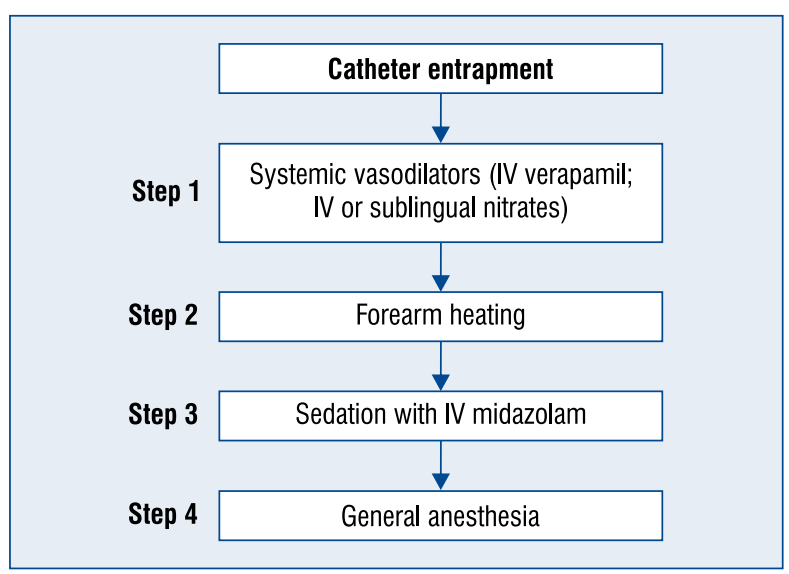

Figure 3. The algorithm used for the treatment of catheter entrapment due to severe radial artery spasm.

in a single, moderate-volume institution. The incidence of catheter entrapment due to severe RAS was extremely low and this might cause the predictors of catheter entrapment to be less reliable. Further prospective studies are warranted to confirm the findings of the present study. Routine forearm angiography was not performed in order to determine radial artery anomaly. In the management of catheter entrapment, administration of incremental doses of intravenous midazolam was not applied and intravenous midazolam dosage is limited to $1-2 \mathrm{mg}$, which may not be enough for some patients. Another limitation may be the absence of routine pre-procedural sedation, which has been well proven to reduce the incidence of radial spasm. The present study did not report the post-procedural complications like hemorrhage or radial artery occlusion, the focus of the study was to describe the incidence, predictors and management of catheter entrapment due to severe RAS.

\section{Conclusions}

Catheter entrapment due to severe RAS during transradial approach was rare and prolonged total procedure time is an independent predictor of catheter entrapment. Treatment with stepwise administration of different treatment modalities is possible with no significant complications.

\section{Conflict of interest: None declared}

\section{References}

1. Caputo RP, Simons A, Gianbartolomei A et al. Transradial cardiac catheterisation in elderly patients. Catheter Cardiovasc Interv, 2000; 51: 287-290.
2. Hildick-Smith DJ, Walsh JT, Lowe MD, Petch MC. Coronary angiography in the fully anticoagulated patient: The transradial route is successful and safe. Catheter Cardiovasc Interv, 2003; 58: 8-10.

3. Kiemeneij F, Laarman GJ, Odekerken D, Slagboom T, Van der Wieken RA. Randomized comparison of percutaneous transluminal coronary angioplasty by the radial, brachial, and femoral approaches: The access study. J Am Coll Cardiol, 1997; 29: 1269-1275.

4. Jolly SS, Yusuf S, Cairns J et al. Radial versus femoral access for coronary angiography and intervention in patients with acute coronary syndromes (RIVAL): A randomised, parallel group, multicentre trial. Lancet, 2011; 377: 1409-1420.

5. Mehta SR, Jolly SS, Cairns J et al. Effects of radial versus femoral artery access in patients with acute coronary syndromes with or without ST-segment elevation. J Am Coll Cardiol, 2012; 60: 2490-2499.

6. Bertrand OF, Rao SV, Pancholy S et al. Transradial approach for coronary angiography and interventions: results of the first international transradial practice survey. J Am Coll Cardiol Cardiovasc Interv, 2010; 3: 1022-1031.

7. Kiemeneij F, Vajifdar BU, Eccleshall SC, Laarman G, Slagboom T, van der Wieken R. Evaluation of a spasmolytic cocktail to prevent radial artery spasm during coronary procedures. Catheter Cardiovasc Interv, 2003; 58: 281-284.

8. Ho HH, Jafary FH, Ong PJ. Radial artery spasm during transradial cardiac catheterization and percutaneous coronary intervention: Incidence, predisposing factors, prevention, and management. Cardiovasc Revasc Med, 2012; 13: 193-195.

9. Goldberg SL, Renslo R, Sinow R, French WJ. Learning curve in the use of the radial artery as vascular access in the performance of percutaneous transluminal coronary angioplasty. Cathet Cardiovasc Diagn, 1998; 44: 147-152.

10. Hildick-Smith DJ, Lowe MD, Walsh JT et al. Coronary angiography from the radial artery: Experience, complications and limitations. Int J Cardiol, 1998; 64: 231-239.

11. Barbeau GR, Arsenault F, Dugas L, Simard S, Lariviere MM. Evaluation of the ulnopalmar arterial arches with pulse oximetry and plethysmography: Comparison with the Allen's test in 1010 patients. Am Heart J, 2004; 147: 489-493.

12. Jia DA, Zhou YJ, Shi DM et al. Incidence and predictors of radial artery spasm during transradial coronary angiography and intervention. Chin Med J (Engl), 2010; 123: 843-847.

13. Goldsmit A, Kiemeneij F, Gilchrist IC et al. Radial artery spasm associated with transradial cardiovascular procedures: Results from the RAS registry. Catheter Cardiovasc Interv, 2014; 83: E32-E36.

14. He GW, Yang CQ. Characteristics of adrenoceptors in the human radial artery: Clinical implications. J Thorac Cardiovasc Surg, 1998; 115: 1136-1141.

15. Kiemeneij F, Fraser D, Slagboom T, Laarman G, van der Wieken R. Hydrophilic coating aids radial sheath withdrawal and reduces patient discomfort following transradial coronary intervention: A randomized double-blind comparison of coated and uncoated sheaths. Catheter Cardiovasc Interv, 2003; 59: 161-164.

16. Varenne O, Jégou A, Cohen R et al. Prevention of arterial spasm during percutaneous coronary interventions through radial artery: The SPASM study. Catheter Cardiovasc Interv, 2006; 68: 231-235.

17. Coppola J, Patel T, Kwan T et al. Nitroglycerin, nitroprusside, or both, in preventing radial artery spasm during transradial artery catheterization. J Invasive Cardiol, 2006; 18: 155-158.

18. Chen CW, Lin CL, Lin TK, Lin CD. A simple and effective regimen for prevention of radial artery spasm during coronary catheterization. Cardiology, 2006; 105: 43-47. 
Cardiology Journal 2016, Vol. 23, No. 3

19. Rosencher J, Chaib A, Barbou F et al. How to limit radial artery spasm during percutaneous coronary interventions. The SPasmolytic Agents to avoid SpasM during transradial percutaneous coronary interventions (SPASM3) study. Catheter Cardiovasc Interv, 2014; 84: 766-771.

20. Hizoh I, Majoros Z, Major L et al. Need for prophylactic application of verapamil in transradial coronary procedures: A randomized trial. The VITRIOL (is Verapamil In TransRadial Interventions OmittabLe?) trial. J Am Heart Assoc, 2014; 3: e000588.

21. Kassimis G, Channon KM, Hahalis G et al. Transradial arterial access catheter knots: How to stay out of trouble. Minerva Cardioangiol, 2015; 63: 449-456.

22. Ercan S, Davutoglu V, Yuce M. Anxiety score as a risk factor for radial artery spasm during transradial procedures. J Am Coll Cardiol Cardiovasc Interv, 2013; 6: 1214-1215.

23. Sciahbasi A, Romagnoli E, Trani $\mathrm{C}$ et al. Evaluation of the "learning curve" for left and right radial approach during percutaneous coronary procedures. Am J Cardiol, 2011; 108: 185-188.

24. Kiemeneij F. Prevention and management of radial artery spasm. J Invasive Cardiol, 2006; 18: 159-160.
25. Osman F, Buller N, Steeds R. Use of intra-arterial papaverine for severe arterial spasm during radial cardiac catheterization. J Invasive Cardiol, 2008; 20: 551-552.

26. Bellien J, Thuillez C, Joannides R. Role of endothelium-derived hyperpolarizing factor in the regulation of radial artery basal diameter and endothelium-dependent dilatation in vivo. Clin Exp Pharmacol Physiol, 2008; 35: 494-497.

27. Ives SJ, Andtbacka RH, Noyes RD et al. Human skeletal muscle feed arteries studied in vitro: The effect of temperature on alpha(1) -adrenergic responsiveness. Exp Physiol, 2011; 96: 907-918.

28. Deftereos S, Giannopoulos G, Raisakis K et al. Moderate procedural sedation and opioid analgesia during transradial coronary interventions to prevent spasm: A prospective randomized study. J Am Coll Cardiol Cardiovasc Interv, 2013; 6: 267-273.

29. Colussi GL, Di Fabio A, Catena C, Chiuch A, Sechi LA. Involvement of endothelium-dependent and -independent mechanisms in midazolam-induced vasodilation. Hypertens Res, 2011; 34: 929-934.

30. Pullakhandam NS, Yang ZJ, Thomas S, Wasenko J. Unusual complication of transradial catheterization. Anesth Analg, 2006; 103: 794-795. 